\title{
Arte Rupestre de México Oriental y de Centro América'
}

\section{Martin Künne y Matthias Strecker}

\section{INTRODUCCIÓN}

De todas las manifestaciones culturales que han dejado los indígenas de México y de América Central, los grabados y pinturas rupestres han recibido la menor atención. Aunque las representaciones rupestres pertenecen a los monumentos arqueológicos más visibles, solo raras veces se las incluyó en investigaciones sistemáticas. Desde los primeros informes y noticias de la mitad del siglo XIX se dejó su documentación a menudo a aficionados e investigadores autodidactas. De la misma manera se nota que tampoco la literatura especializada actual toma en cuenta las representaciones rupestres de la región. A pesar de que el recién editado "Handbook of Rock Art Research" (Whitley 2001) comprende cuatro regiones americanas, faltan completamente Mesoamérica y América Central. Por otro lado podemos constatar que muchas documentaciones e informes sobre el arte rupestre centroamericano han sido parciales y hacen difícil una visión del conjunto. Sus enfoques se limitan normalmente a perspectivas descriptivas. Solamente algunas tienen también carácter analítico (A. Stone 1995). Entre los pocos compendios que mencionan representaciones rupestres de México y de América Central están las publicaciones "Rock Art Studies: News of the World I" (Bahn y Fossati 1996) y “Arte Prehistórico de América” (Schobinger 1997).

Nuestro libro tiene carácter bibliográfico. Su propósito es ser una guía para la búsqueda de fuentes de información y ofrecer una introducción al estudio sistemático del arte rupestre en el oriente de México y en Centroamérica; ampliando y actualizando la publicación anterior "Rock Art of East Mexico and Central America" (Strecker 1979). Se dirige tanto a especialistas, estudiantes y aficionados como a propietarios o indígenas quienes asuman el rol de "custodios naturales" de sitios con representaciones rupestres. Comprende dos partes: una bibliografía anotada y resúmenes de las investigaciones regionales, complementados por ilustraciones representativas.

Presentamos el arte rupestre según la distribución política de los estados en el oriente de México y América Central. La bibliografía comprende tanto una lista regional como una lista alfabética de autores. Los textos se basan en investigaciones propias de los autores e introducen al lector al estado actual de la investigación del arte rupestre en las regiones respectivas. Los editores entienden la investigación del arte rupestre como estudio multidisciplinario que no se puede separar de la arqueología ni de otras disciplinas científicas. Los autores presentan diferentes estrategias de investigación que dan una visión preliminar y diversa de las imágenes estudiadas. Las cuestiones discutidas corresponden tanto a las características de las representaciones documentadas como al estado de investigación en cada país de la región estudiada.

\section{Espacio geográfico y estrategias de adaptación}

México Oriental y América Central se extienden desde el Istmo de Tehuantepec (México) hasta la Cuenca del Río Atrato (Colombia). Incluyen tres paisajes principales: las llanuras extensas del lado caribeño, las cordilleras centrales y el litoral pacífico con sus bocas, islas y numerosas penínsulas. Las diferentes regiones ofrecen una multitud de zonas vegetales y climáticas. Alcanzan desde las tierras calientes con una flora y fauna tropical hasta el páramo de las cordilleras altas con su vegetación subalpina. Los diversos paisajes provocaron a través de todos los períodos estrategias diferentes de adaptación de los grupos humanos a las condiciones naturales prevalecentes. Se conocen restos arqueológicos de cazadores tempranos (sitio Turrialba,

$1 \quad$ Este texto es la introducción publicada originalmente en la segunda edición actualizada y aumentada del libro "Arte Rupestre de México Oriental y Centro América”, cuya referencia es la siguiente: Künne, Martin y Matthias Strecker (eds.): 2003 Arte Rupestre de México Oriental y de Centro América. Indiana Beiheft, 16. Berlin: Gebr. Mann Verlag [Re-edición en el año 2008 con el título: Arte Rupestre de México Oriental y de América Central, URL: http://www.siarb-bolivia.org/] 
CRONOLOGÍA

\begin{tabular}{|c|c|c|c|}
\hline $\begin{array}{l}\text { Alta América } \\
\text { Central }\end{array}$ & sitios arqueológicos & $\begin{array}{l}\text { Baja América } \\
\text { Central }\end{array}$ & $\begin{array}{l}\text { sitios arqueológicos e } \\
\text { históricos }\end{array}$ \\
\hline $\begin{array}{l}\text { Postclásico Tardío } \\
\text { (1530-1200 d.C.) }\end{array}$ & $\begin{array}{l}\text { Iximche', Mayapan, Tayasal, } \\
\text { Tulum }\end{array}$ & \multirow[t]{2}{*}{$\begin{array}{l}\text { Periodo VI } \\
(1520-1000 \text { d.C. })\end{array}$} & Couto, Parita, Tecoatega \\
\hline \multirow{2}{*}{$\begin{array}{l}\text { Postclásico } \\
\text { Temprano } \\
(1200-900 \text { d.C. })\end{array}$} & \multirow[t]{2}{*}{ Chichen Itza, Uxmal, } & & Naco, Cihuatan \\
\hline & & \multirow[t]{4}{*}{$\begin{array}{l}\text { Período V } \\
(1000-500 \text { d.C.) }\end{array}$} & \multirow{4}{*}{$\begin{array}{l}\text { Quelepa, Tenampua } \\
\text { (1000-500 d.C.) } \\
\text { Sitio Conte, Guayabo } \\
\text { (900-400 d.C.) } \\
\text { Barriles } \\
\text { (600-200 d.C.) }\end{array}$} \\
\hline $\begin{array}{l}\text { Clásico Terminal } \\
\text { (900-800 d.C.) }\end{array}$ & $\begin{array}{l}\text { Kabah, Sayil, } \\
\text { Estela de Tonina }\end{array}$ & & \\
\hline $\begin{array}{l}\text { Clásico Tardio } \\
\text { (800-600 d.C.) }\end{array}$ & $\begin{array}{l}\text { Copán, Tikal } \\
(800-400 \text { d.C.) }\end{array}$ & & \\
\hline \multirow{2}{*}{$\begin{array}{l}\text { Clásico Temprano } \\
\text { (600-250 d.C.) }\end{array}$} & \multirow{2}{*}{$\begin{array}{l}\text { Cotzumalhuapa, Palenque, } \\
\text { Yaxchilán }\end{array}$} & & \\
\hline & & \multirow{4}{*}{$\begin{array}{l}\text { Periodo IV } \\
(500 \text { d.C. }-1000 \\
\text { a.C.) }\end{array}$} & \multirow{4}{*}{$\begin{array}{l}\text { Cerro Zapote } \\
\text { (1000 d.C. }-300 \text { a.C.) } \\
\text { Playa de los Muertos } \\
(300-600 \text { a.C. })\end{array}$} \\
\hline $\begin{array}{l}\text { Preclásico Tardio } \\
\text { ( } 250 \text { d.C. }-300 \text { a.C.) }\end{array}$ & $\begin{array}{l}\text { Izapa (200 d.C. }-400 \text { a.C.) } \\
\text { El Mirador (100 d.C. }-150 \text { a.C.), } \\
\text { Dzibilchaltún }\end{array}$ & & \\
\hline $\begin{array}{l}\text { Preclásico Medio } \\
(300-900 \text { a.C.) }\end{array}$ & $\begin{array}{l}\text { Cuello (400-1000 a.C.) } \\
\text { Loltun (desde } 900 \text { a.C.) } \\
\text { Kaminaljuyú }\end{array}$ & & \\
\hline \multirow{2}{*}{$\begin{array}{l}\text { Preclásico } \\
\text { Temprano } \\
(900-1600 \text { a.C.) }\end{array}$} & \multirow[b]{2}{*}{$\begin{array}{l}\text { Chalchuapa } \\
\text { (desde } 1200 \text { a.C) } \\
\text { Cerámica de Ocos } \\
(1500 \text { a.C.) } \\
\text { Cerámica de Altamira } \\
\text { (1600 a.C.) }\end{array}$} & & \\
\hline & & \multirow[t]{3}{*}{$\begin{array}{l}\text { Período III } \\
(1000-4000 \text { a.C. })\end{array}$} & $\begin{array}{l}\text { La Rama } \\
\text { (1500 a.C.?) } \\
\text { Cerámica de Monagrillo } \\
\text { (2130 a.C.) }\end{array}$ \\
\hline $\begin{array}{l}\text { Arcaico Tardio } \\
\text { (1600-2000 a.C.) }\end{array}$ & Cueva Sta. Marta & & \\
\hline \multirow[t]{2}{*}{$\begin{array}{l}\text { Arcaico Medio } \\
(2000-5000 \text { a.C. })\end{array}$} & & & $\begin{array}{l}\text { Boquete, Esperanza } \\
\text { (4000 a.C.?) }\end{array}$ \\
\hline & $\begin{array}{l}\text { Los Tapiales } \\
\text { (aprox. } 5000 \text { a.C.?) }\end{array}$ & \multirow[t]{3}{*}{$\begin{array}{l}\text { Período II } \\
(4000-8000 \text { a.C.) }\end{array}$} & $\begin{array}{l}\text { Acahualinca } \\
(4000 \text { a.C.?) }\end{array}$ \\
\hline \multirow[t]{2}{*}{$\begin{array}{l}\text { Arcaico Temprano } \\
\text { (5000-8000 a.C.) }\end{array}$} & $\begin{array}{l}\text { San Rafael } \\
(5000 \text { a.C.?) }\end{array}$ & & $\begin{array}{l}\text { Cerro Mangote } \\
(4858 \text { a.C.) }\end{array}$ \\
\hline & $\begin{array}{l}\text { Orange Walk } \\
(8000 \text { a.C.?) }\end{array}$ & & \\
\hline \multirow[t]{2}{*}{$\begin{array}{l}\text { Paleoindio } \\
\text { (desde } 8.000 \text { a.C.) }\end{array}$} & \multirow[b]{2}{*}{$\begin{array}{l}\text { Los Grifos } \\
\text { (11.000 a.C.?) }\end{array}$} & \multirow[t]{2}{*}{$\begin{array}{l}\text { Periodo I } \\
\text { (desde } 8000 \text { a.C.) }\end{array}$} & \\
\hline & & & $\begin{array}{l}\text { Guardiria } \\
\text { (11.000 a.C.?) } \\
\text { Isla Macapala } \\
\text { (11.000 a.C.?) }\end{array}$ \\
\hline
\end{tabular}

Cronología general y sitios arqueológicos de México y de América Central. Las fechas locales indican a los periodos de utilización principal de cada sitio. 
Costa Rica; isla Macapala, Panamá), de poblaciones con economía marítima o fluvial (sitio Orange Walk, Belice), de recolectores de frutas arbóreas (sitio Casita de Piedra, Panamá), de agricultores (sitio El Cerrén, El Salvador) y de grupos con una economía mixta (sitio La Esperanza, Honduras). En la península de Yucatán, en Chiapas, en Guatemala, en El Salvador y en el occidente de Honduras se encontraron grandes centros políticos con una arquitectura monumental, por otro lado en los países sureños de América Central predominan asentamientos agrarios más pequeños.

\section{Espacio cultural y períodos arqueológicos}

Desde una perspectiva horizontal se distinguen en América Central dos grandes espacios culturales (Fig. 1). La región al norte del río Ullua (Honduras Occidental) y del río Lempa (El Salvador) se denomina Alta América Central. Está caracterizada por fuertes influencias de las culturas mayas y mexicanas y forma parte integral de Mesoamérica. Por el contrario, Baja América Central comprende los territorios al sur de ambas corrientes fluviales. Aquí prevalecen tradiciones suramericanas (Baudez 1970: 17-23, 33, 34; Lange y D. Stone 1984: 4, fig. 1.1). A causa de su situación entre los estados complejos de Mesoamérica y los estados de la Cordillera Andina, se conoce la misma región también bajo el nombre de Zona Intermedia (Haberland 1959: 2). En la región sureña casi no se conocen horizontes culturales y sociedades altamente estratificadas, sin embargo se documentaron muchos objetos arqueológicos que muestran claramente influencias mesoamericanas. Por otro lado aparecieron tecnologías y tradiciones de Baja América Central también en los centros culturales de México Oriental. Por eso se piensa hoy que ambas zonas de América Central formaban complejos culturales que se compenetraban una con otra. No parece que representaran espacios uniformes con fronteras fijas y cerradas (Schortman y Urban 2001: 365-371).

Los estudios sobre las culturas de Alta América Central se basan en la documentación de contextos arqueológicos, en investigaciones iconográficas y en informaciones escritas; mientras que se conocen las culturas precolombinas de Baja América Central casi exclusivamente a través de los restos encontrados en el suelo y de las modificaciones del paisaje natural. Según la secuencia principal se diferencia para Alta América Central los siguientes períodos cronológicos: Paleoindio (hasta 8000 a.C.), Arcaico (8000-2000 a.C.), Preclásico o Formativo (2000 a.C.-250 d.C.), Clásico (250900 d.C.) y Postclásico (900-1530 d.C.) (Grube 2001). La prehistoria de Baja América Central se divide por el contrario en seis períodos: período I (hasta 8.000 a.C.), período II (8000-4000 a.C.), período III (4000-1000 a.C.), período IV (1000 a.C.-500 d.C.), período V (500-1000 d.C.) y período VI (1000-1500 d.C.) (Lange y D. Stone 1984: 7). Dentro de ambas secuencias existe una multitud de fases que reflejan las particularidades regionales y locales de desarrollo. En Alta América Central se pueden reconocer horizontes ("olmeca", Teotihuacán, "maya") y tradiciones culturales (Usulután, Ullua policromo, Mixteca-Puebla) ampliamente difundidos. En Baja América Central se encontraron solamente tradiciones regionales (Fig. 2). Las excepciones únicas son tal vez los horizontes de las cerámicas Bicromo en zonas y de los objetos de arcilla con capa crema.

\section{La distribución de representaciones rupestres}

Se pueden diferenciar sitios, zonas y regiones con arte rupestre. Los sitios con arte rupestre están formados por espacios diversos (salas, corredores, farallones, etc.) o de objetos (piedras, rocas, etc.) decorados. Las zonas rupestres comprenden a menudo paisajes enteros (valles, altiplanicies, llanuras). Las regiones con arte rupestre coinciden al contrario con macroestructuras geológicas (Cordillera Andina) o con regiones ecológicas (Selva Amazónica). La distribución geográfica de las representaciones rupestres conocidas depende de muchos factores, que incluyen el estado de su preservación, el nivel de su investigación o las intenciones de sus creadores. Mientras que las extensas cuevas calcáreas de Alta América Central no contienen más de 40 sitios con arte rupestre (A. Stone 1995: 45), casi no se conocen representaciones subterráneas de Baja América Central. Aunque sus cordilleras volcánicas forman también una gran cantidad de cuevas, grutas y cavernas, la gran mayoría de su arte rupestre se encuentra al aire libre. La zona Pacífica de Nicaragua, las cuevas de la región Petexbatún o las barrancas de Chiapas recibieron una mayor atención científica. En cambio, el Darién panameña, la Talamanca Alta de Costa Rica o las llanuras atlánticas de Honduras y de Nicaragua carecieron siempre de investigaciones sistemáticas. Por eso no sorprende que la cantidad registrada de sus sitios rupestres es muy baja.

\section{Contextos arqueológicos y representaciones rupestres}

En muchas partes del mundo se entienden las representaciones rupestres como testimonios de cazadores y recolectores, pero en América Central no se encontraron asociaciones directas entre imágenes rupestres y contextos precerámicos. Se supone por eso que el arte rupestre 
centroamericano no tiene más de 4000 años de edad y es principalmente producto de agricultores de vida sedentaria. Mientras que unos motivos de Alta América Central indican por sus atributos de rango a sociedades estratificadas, la mayoría del arte rupestre de toda la región carece de aspectos que lo vinculen con distintas capas sociales. Aunque se conoce en Baja América Central arte rupestre de algunos centros políticos, parece que la mayoría de las representaciones conocidas se relaciona con lugares lejos de asentamientos. A menudo se las reporta de lugares especiales del paisaje natural (cuevas, aleros, paredes rocosas, rápidos, penínsulas, volcanes) o de rutas de intercambio cultural (caminos de comercio, rutas de peregrinaje). La escasez de asociaciones directas entre materiales arqueológicos y representaciones rupestres complica en muchos casos la determinación de su función y de su contenido simbólico.

\section{Períodos y regiones estilísticas del arte rupestre}

Aunque en México y América Central se conocen diferentes estilos iconográficos de la cerámica, de murales y de códices, la clasificación de regiones y secuencias estilísticas de su arte rupestre todavía se encuentra al comienzo de la investigación. Los estilos de Alta América Central se vinculan más con períodos cronológicos que con territorios bien limitados, sin embargo, las dataciones de representaciones rupestres de Baja América Central proceden a menudo de contextos arqueológicos particulares. Para conclusiones fehacientes sobre la cronología se necesita en ambas regiones urgentemente investigaciones más amplias.

D. Stone (1948: 170, 191) presume que los grabados rupestres de América Central son indicadores del horizonte Formativo, aunque le parece imposible asignarlos a alguna cultura en particular. Por otro lado, Krickeberg (1949: 74 ss.) relaciona el arte rupestre de Baja América Central con seis culturas y poblaciones específicas. Ambos conceptos se basan en una teoría evolucionista que presume un desarrollo linear de formas simples y abstractas a imágenes realistas y detalladas. A diferencia de este modelo bipolar, ahora se explican las diferencias estilísticas también por características sociales y funcionales. Mientras que los estilos iconográficos pueden servir como indicador cultural en regiones con una gran diversidad arqueológica, en zonas

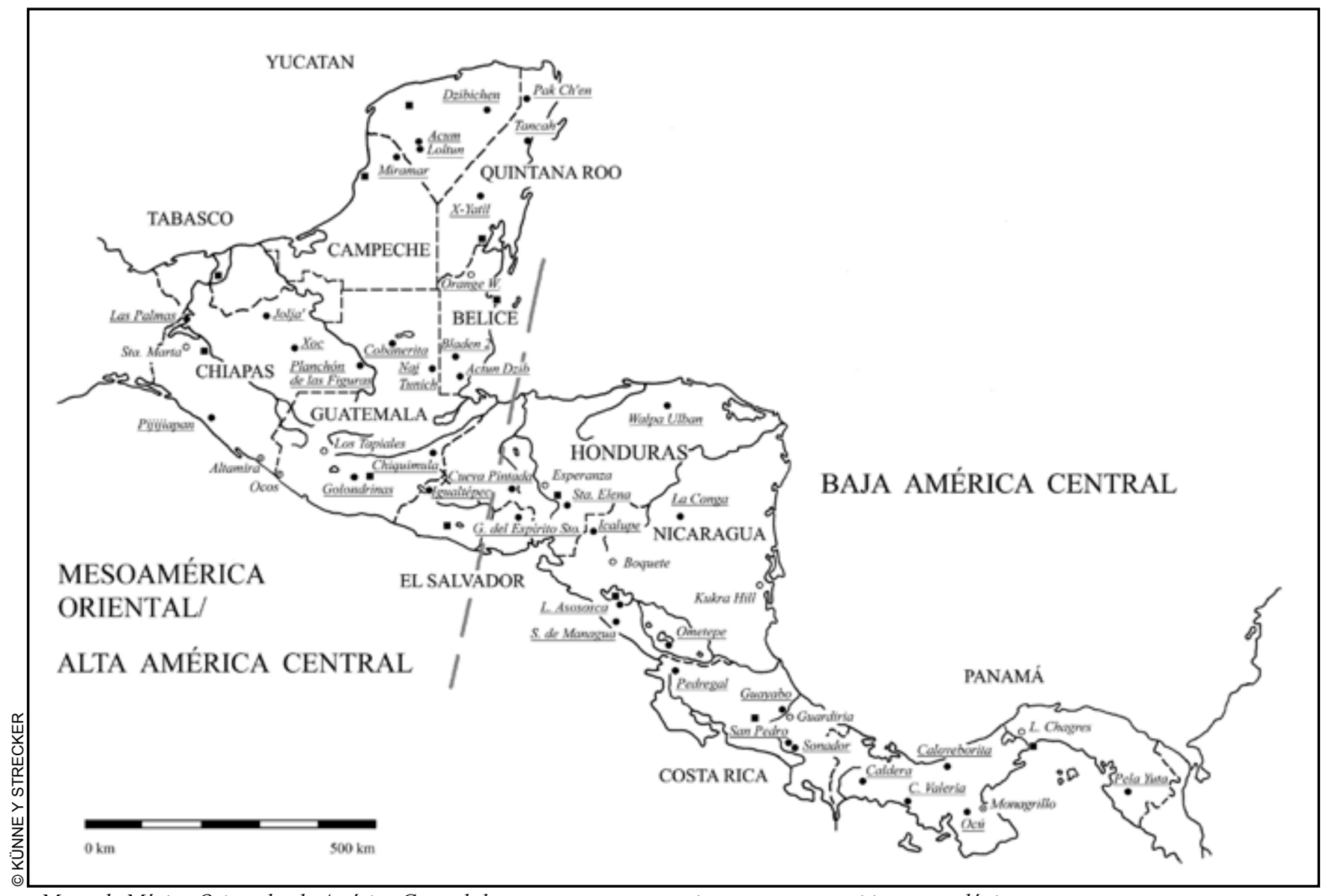

Mapa de México Oriental y de América Central: lugares con representaciones rupestres y sitios arqueológicos. 
sin importantes cambios culturales más probablemente señalan diferentes grupos étnicos, zonas de utilización o clases de género.

Según el estado actual de la investigación, se puede distinguir entre motivos distribuidos a través de toda América Central y formas iconográficas limitadas a regiones o períodos particulares. Mientras que simples líneas, espirales y caras forman la mayoría de todas las representaciones - tanto en las cuevas de Yucatán como en el sur de Costa Rica -, se conocen figuras antropomorfas detalladas y serpientes plumadas solo de Alta América Central.

Las representaciones más antiguas de México Oriental y Centroamérica tal vez se encuentren en la Cueva Loltun (Yucatán), en la Cueva Santa Marta (Chiapas), en el abrigo El Gigante (Honduras) y en la Cueva del Espírito Santo (El Salvador). Consisten en impresiones de manos positivas (Cueva Loltun, Cueva Santa Marta, El Gigante) o en simples pinturas antropomorfas no clasificadas (Cueva Santa Marta, Cueva del Espírito Santo). A pesar de que en todos estos sitios se encontraron artefactos precerámicos, no existen dataciones absolutas ni asociaciones directas.

En el arte rupestre de Alta América Central aparecen con la tradición olmeca monumentales relieves altos y pinturas policromas. Tienen carácter semi-escénico y representan a menudo grupos de figuras antropomorfas. Se los conoce tanto de los sitios Xoc y Pijijiapan en Chiapas (México) como de regiones vecinas de Mesoamérica (sitios Juxtlahuaca y Oxtotitlán en Guerrero). El estilo epi-olmeco del Preclásico Tardio se caracteriza al contrario por grabados rupestres que cubren toda la superficie de los objetos decorados sin dejar ningún espacio que no haya sido trabajado. Ejemplos de esto se hallan en Izapa (Chiapas), Sta. Leticia (El Salvador), Nakbe (Guatemala) o en El Mirador (Guatemala).

La mayoría de las pinturas y grabados rupestres que se pueden adscribir al período Clásico se encuentra en las cuevas de la península Yucatán, del estado Chiapas (México) y del Petén (Guatemala). A veces están acompañados de inscripciones que indican la procedencia y el rango de las figuras representadas. Algunas representaciones demuestran actos rituales, otras parecen configurar escenas míticas. El corpus mayor comprende 89 complejos pintados (A. Stone 1995) en la cueva Naj Tunich (Guatemala). La mayoría de las imágenes analizadas pertenece al Clásico Tardio (600-900 d.C.), pero se conoce también una fecha del Clásico Temprano (250-400 d.C.) de la cueva Joloniel (Chiapas). Muchas cuevas de Alta América Central poseen un estilo particular de decoración y solamente en la zona Puuc (Yucatán) se ha registrado una

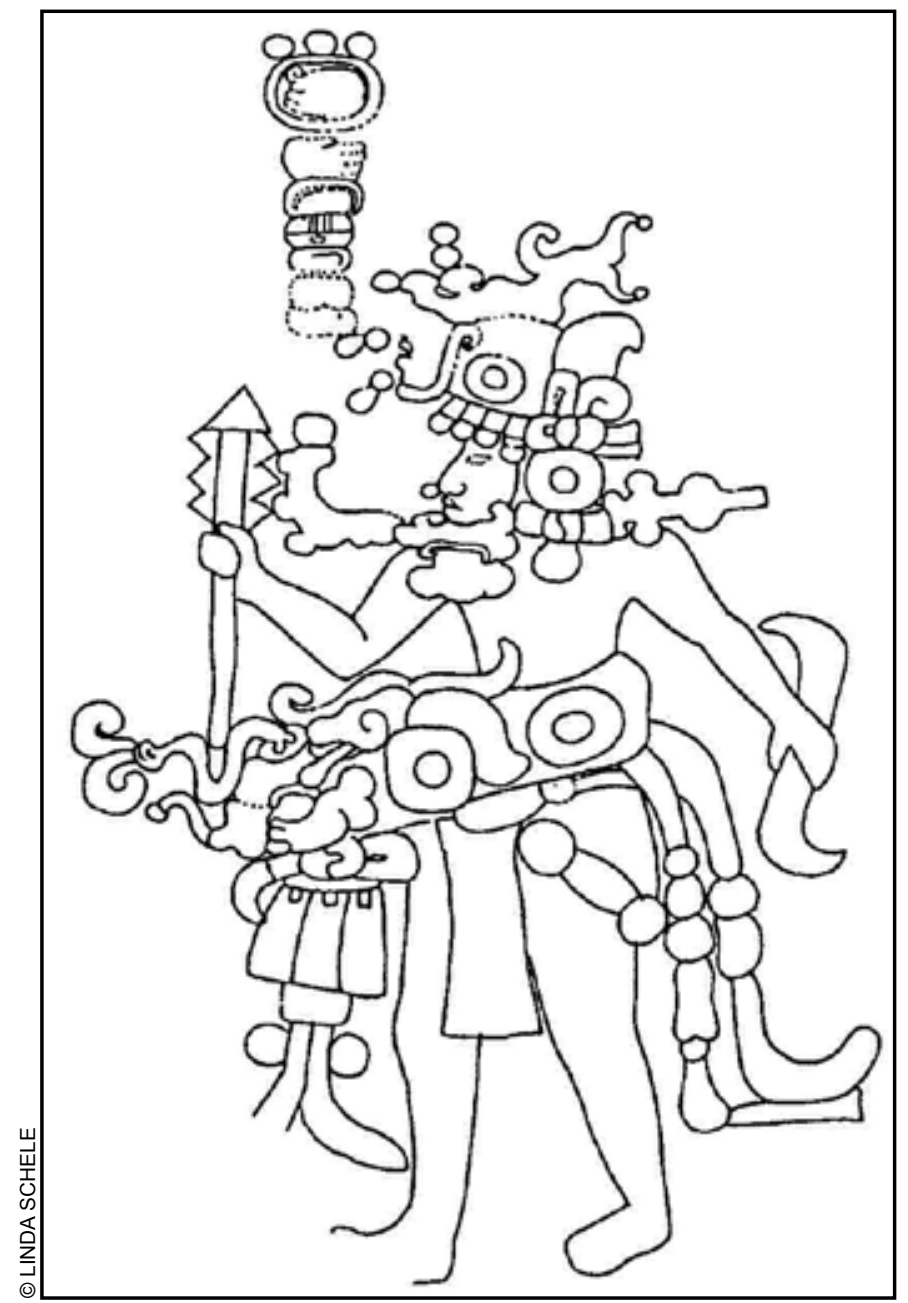

Bajo relieve de la entrada de Hunacab de la cueva de Loltun, Estado Yucatán, México.

tradición regional, la que consiste en pinturas grandes con pocos detalles. Representan cabezas, siluetas o improntas de manos (ver el artículo de Strecker y A. Stone en este libro). En las altiplanicies de Guatemala se registró hasta el presente una sola cueva pintada.

Las iconografías rupestres que son características del Postclásico incluyen motivos conocidos de códices y cerámicas policromas. El estilo Mixteco-Puebla utiliza colores fuertes y elementos estandarizados que denotan seres divinos de las regiones Oaxaca y Puebla. Entre los raros ejemplos de este estilo en el oriente de México se hallan las pinturas antropomorfas del alero Naranjo (Chiapas) (Navarrete 1960: 8-9, figs. 7-9). Algunas pinturas en la cueva Dzibichen de la península de Yucatán recuerdan por sus figuras y formas disproporcionadas al estilo del Códice de Madrid (A. Stone 1995: 82 s.) e indican posiblemente la disolución de esquemas tradicionales de representación. Imágenes coloniales solo se conocen de 
algunos sitios en Chiapas (Nido de Aguila) y en la península de Yucatán (cuevas Dzibichen y Miramar). Algunas de esas representaciones parecen motivos del Chilam Balam de Chumayel, otras muestran jinetes (cueva Miramar) o águilas con dos cabezas (A. Stone 1995: 87, fig. 4-87).

En contraste a la región más norteña, en Baja América Central existen solo clasificaciones iconográficas con carácter tentativo y en nivel sincrónico. El modo abstracto de la mayoría de su arte rupestre dificulta el establecimiento de secuencias cronológicas que se basen en aspectos diagnósticos. Sin embargo se supone que buena parte de las representaciones rupestres del Pacífico sur de Costa Rica corresponden por su estilo curvilinear a los períodos $\mathrm{V}$ y VI (Quilter y Blanco 1992: 13). Aunque la mayoría de los motivos de todas las regiones centroamericanas presenta formas geométricas, parece que la zona de Gran Nicoya tiene una cantidad más alta de imágenes figurativas que los territorios más sureños. Muchas representaciones del Pacífico Sur de Costa Rica consisten en espirales, líneas y círculos vinculados, por otro lado los artesanos de la región central de Panamá utilizaron otro inventario formal (Harte $1961 \mathrm{a}, \mathrm{b}$ ). Motivos parecidos a gusanos o ciempiés recuerdan a imágenes parecidas de culturas andinas. A causa de la escasez de documentaciones en la región Atlántica no se puede decir nada sobre la semejanza de sus representaciones con las del litoral Pacífico.

Los estilos esbozados representan solo una parte mínima de toda la variedad iconográfica de América Central. Según una primera impresión corresponden a la separación cultural de la región en dos macroregiones grandes. Una segunda mirada muestra sin embargo que hay múltiples fusiones. Sin embargo hay que recordar que la identificación de complejos iconográficos depende también de presuposiciones culturales. Solo en relación a las informaciones contextuales se puede decidir si un águila con dos cabezas indica al escudo de la familia real de Habsburgo o motivos prehispánicos.

\section{Historia de investigación e interpretación}

La investigación del arte rupestre de México y América Central se vincula estrechamente con el desarrollo teórico en la antropología, en la arqueología, en la lingüística y en las ciencias del arte. Los primeros viajeros (Bancroft, Bovallius, Bransford, Flint, Maler, McNeil, Seemann, Squier) y científicos (Hartman, Sapper, Seler, Wagner) que atravesaron los estados de América Central en el siglo XIX entendieron los monumentos arqueológicos como parte de los yacimientos naturales de los estados investigados. Del punto de vista de un investigador moderno, asombra la incapacidad de muchos investigadores tempranos para apreciar las representaciones rupestres como testimonios culturales. Aunque dejaron dibujos en escala de algunos complejos espectaculares, los adscribieron en sus noticias escuetas a un estado infantil del desarrollo cultural y psicológico de la humanidad (Sapper 1900b [1902]: 259). Otros autores entendieron los motivos rupestres como sistemas de escritura y trataron de encontrar sus orígenes en el mundo antiguo (Seemann 1866).

Con el fortalecimiento de estudios histórico-clasificatorios y el descubrimiento de los murales extraordinarios de Alta América Central, se reconocieron las representaciones rupestres como símbolos que indican ideas y conceptos religiosos de las antiguas culturas indígenas. Se conocen de este período principalmente investigaciones selectivas que se concentraron en la documentación y descripción de las iconografías encontradas (D. Stone y Kutscher 1991). Por la suposición de una historia ininterumpida se las vinculó a menudo directamente con motivos semejantes de otras regiones geográficas o de pueblos indígenas del presente. Se entendieron los resultados de excavaciones sistemáticas como documentación de relaciones externas entre diferentes círculos culturales (Kulturkreise), pero se apreciaron los estudios iconográficos como investigación de sus lazos internos.

El enfoque descriptivo-diacrónico buscó por el contrario los significados de objetos y representaciones arqueológicos dentro de las secuencias cronológicas. Aunque en otras partes del mundo estudios estructuralistas explicaron los motivos rupestres de sus asociaciones iconográficas tomando como modelo gramáticas genéricas de la lingüística, en Centroamérica las documentaciones del arte rupestre estuvieron desplazadas al trasfondo de las investigaciones científicas. A pesar de investigaciones reiteradas de los mismos sitios, la mayoría de las representaciones rupestres hasta ahora no es fechable ni directamente asociable a contextos arqueológicos.

Tampoco la arqueología procesual ha estado muy interesada en estudios iconográficos. En lugar de buscar los orígenes y la extensión de las culturas antiguas, se quería explicar los motivos de sus cambios. Se limitó los fenómenos sociales a la interrelación de grupos humanos con su medio ambiente y se subestimaron las dinámicas culturales y sus representaciones. Mientras que se reconocieron contextos arqueológicos como informaciones objetivas, se supuso detrás de las representaciones iconográficas significados no reconstruibles, cuyas interpretaciones siempre serían especulativas. Los pocos estudios rupestres 
que se realizaron durante este período de investigación se dedicaron a representaciones que se encuentran dentro de contextos arqueológicos. Sus interpretaciones rechazaron usualmente analogías históricas y acentuaron el carácter funcional y público de las imágenes investigadas. Se presentaron descripciones e interpretaciones que entienden las representaciones rupestres como "escudos" de grupos sociales o marcadores geográficos.

\section{Estado actual y perspectivas de la investigación}

Actualmente la investigación del arte rupestre se caracteriza por una doble revolución: la de los medios técnicos de documentación y la de los modelos analíticos de interpretación. Fotografías digitales, mediciones geográficas por satélite, dataciones directas y sistemas de información digital permiten hoy la visualización y el análisis de una cantidad enorme de datos nuevos. Las dataciones directas pueden relacionar pinturas rupestres por primera vez a sus contextos arqueológicos. Aunque los métodos de AMS (espectrogrametría por aceleración de masas) y de CR (correlación de cationos) facilitan el análisis de colores, de aglutinantes, de inclusiones orgánicas y de la pátina lítica,

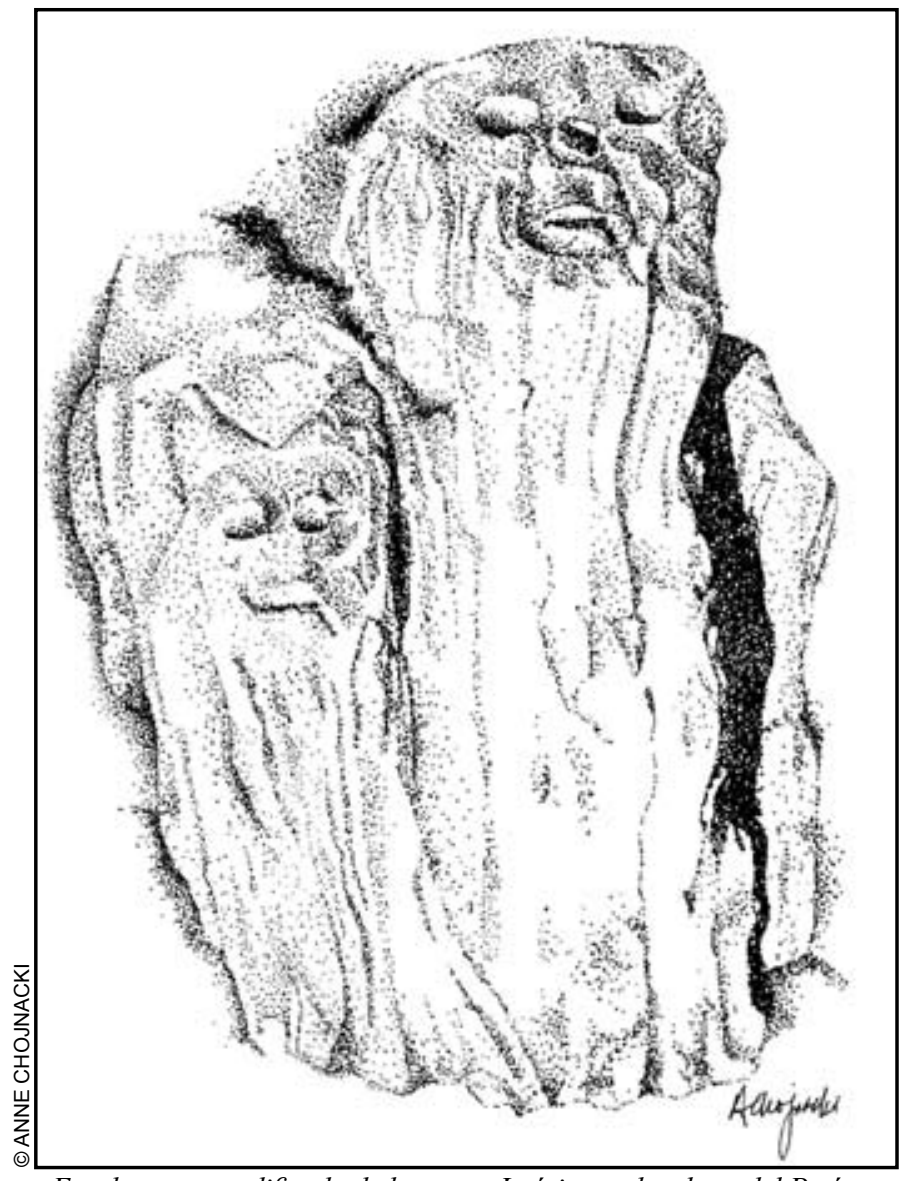

Espeleotema modificada de la cueva Jutéria en el sudeste del Petén, Guatemala. solamente en la cueva Naj Tunich (Armitage et al. 2001), en el sitio del Cerro de la Mariposa, Amatititlán (reportado en el informe sobre el III Coloquio Guatemalteco de Arte Rupestre en el año 2002 y publicado en la revista U tz'ib, 3(3): 26, Guatemala) y en Actun Ik, una cueva en la región Sibun-Manatee, Belice (Rowe et al. 2002), fueron aplicados con éxito estos nuevos métodos (A. Stone y Künne 2003). Ambos procedimientos ofrecen informaciones más exactas, pero todavía se encuentran en proceso de desarrollo y dependen de la constancia de una multitud de factores ambientales y de curvas exactas de medición.

Los nuevos métodos técnicos de documentación requieren no solo equipos especializados e investigaciones a largo plazo sino también una revisión de esquemas antiguos de interpretación. A diferencia a los modelos evolucionarios del pasado, el enfoque "postestilístico" (que ya no depende exclusivamente del análisis de supuestos estilos) permite reconocer la simultaneidad de diferentes estilos y formas de representación. Aunque parece que muchas formas iconográficas existen a través de toda América, siempre hay que buscar su valor simbólico en relación a la práctica social de grupos locales o a redes de interacción regional. Por eso muchas investigaciones actuales tratan de vincular las representaciones documentadas con los conocimientos contextuales que cada vez son mayores. Estudios modernos reflejan enfoques funcionales, ecológicos y etnográficos.

En las discusiones de los últimos decenios, se ha puesto énfasis en la subjetividad de diferentes modelos de interpretación del arte rupestre, cuya veracidad no se puede comprobar (Bednarik 2001, capítulo 8). De esta manera se tiene conciencia del alcance corto de diferentes interpretaciones, sobre todo si faltan asociaciones arqueológicos directos o informaciones sobre sus creadores. Dadas estas limitaciones, los investigadores deben realizar investigaciones multidisciplinarias tratando de llegar a conclusiones fehacientes sobre la datación del arte rupestre y usando diferentes métodos de interpretación. "Métodos formales", como el estudio de las técnicas de producción usadas, de las formas de representación de las figuras o de la distribución de los sitios en el paisaje sirven a la investigación de las fuentes disponibles de información objetiva. "Métodos informados", que cuentan con relatos de parte de los artistas mismos o de la gente que usaba los sitios de arte rupestre, pueden relacionar los sitios investigados a través de fuentes etnográficas, etnohistóricas o históricas a diferentes funciones sociales. También informaciones etnográficas no relacionadas directamente con el arte rupestre podrían ser válidas para explicar el contenido de los grabados o pinturas (Chippindale 2001: 262-264). En 
cualquier caso, es imprescindible presentar la interpretación como hipotética que no excluya otras posibilidades.

\section{Registro y documentación}

En algunos países del mundo (Sudáfrica, Australia, Brasil, España, Francia) la investigación de representaciones rupestres forma una parte integral de la arqueología. Sin embargo, en América Central los estudios del arte representan todavía un sector subordinado de la ciencia. No solo faltan a menudo ofertas de formación universitaria, sino también el acceso a la literatura actual y a métodos modernos de documentación. Mientras que a escala internacional se aplican principalmente procedimientos de documentación que no afectan la preservación de las representaciones investigadas, todavía hay que crear esta conciencia en muchas regiones de Centroamérica. A pesar de la variedad considerable de las representaciones conocidas, faltan documentaciones sistemáticas y estudios analíticos que desarrollen una perspectiva comparativa. Hasta hoy predominan las documentaciones locales realizadas por investigadores autodidactas y aficionados.

A. Stone (Universidad de Wisconsin) documentó representaciones rupestres de la península de Yucatán (estados
Campeche y Yucatán), de las llanuras del Petén guatemalteco (cueva Naj Tunich), de las cordilleras de Guatemala y del Lago Güija (El Salvador). J. Brady (Universidad de California Los Angeles) trabajó en la documentación del arte rupestre de la región Petexbatún (Guatemala) y vinculó sus estudios con la investigación de sitios arqueológicos con arquitectura monumental. Ware y Brady (1999) aplicaron técnicas de análisis multiespectral en la investigación de pinturas rupestres de la cueva Naj Tunich. El método permite la identificación de diferentes capas de pintura y la clasificación de recetas de color. Sus resultados pueden servir como base para la determinación de secuencias cronológicas y de talleres de manufactura. Robinson (2000) aplicó el mismo procedimiento en el análisis de representaciones rupestres de la cueva La Casa de las Golondrinas (Guatemala). Un grupo de investigadores guatemaltecos alrededor de Lucrecia de Batres y Edgar Carpio Rezzio (Universidad de San Carlos) se dedica en un proyecto continuo al estudio del arte rupestre del Departamento de Chiquimula y del Lago Amatitlán (Guatemala). Zender, Bassie y Pérez de Lara investigaron nuevamente el arte rupestre de la Cueva Jolja' en Chiapas (México).

Al comienzo de los años 90, Breuil-Martínez (Universidad Paris I) condujo investigaciones arqueológicas en la zona

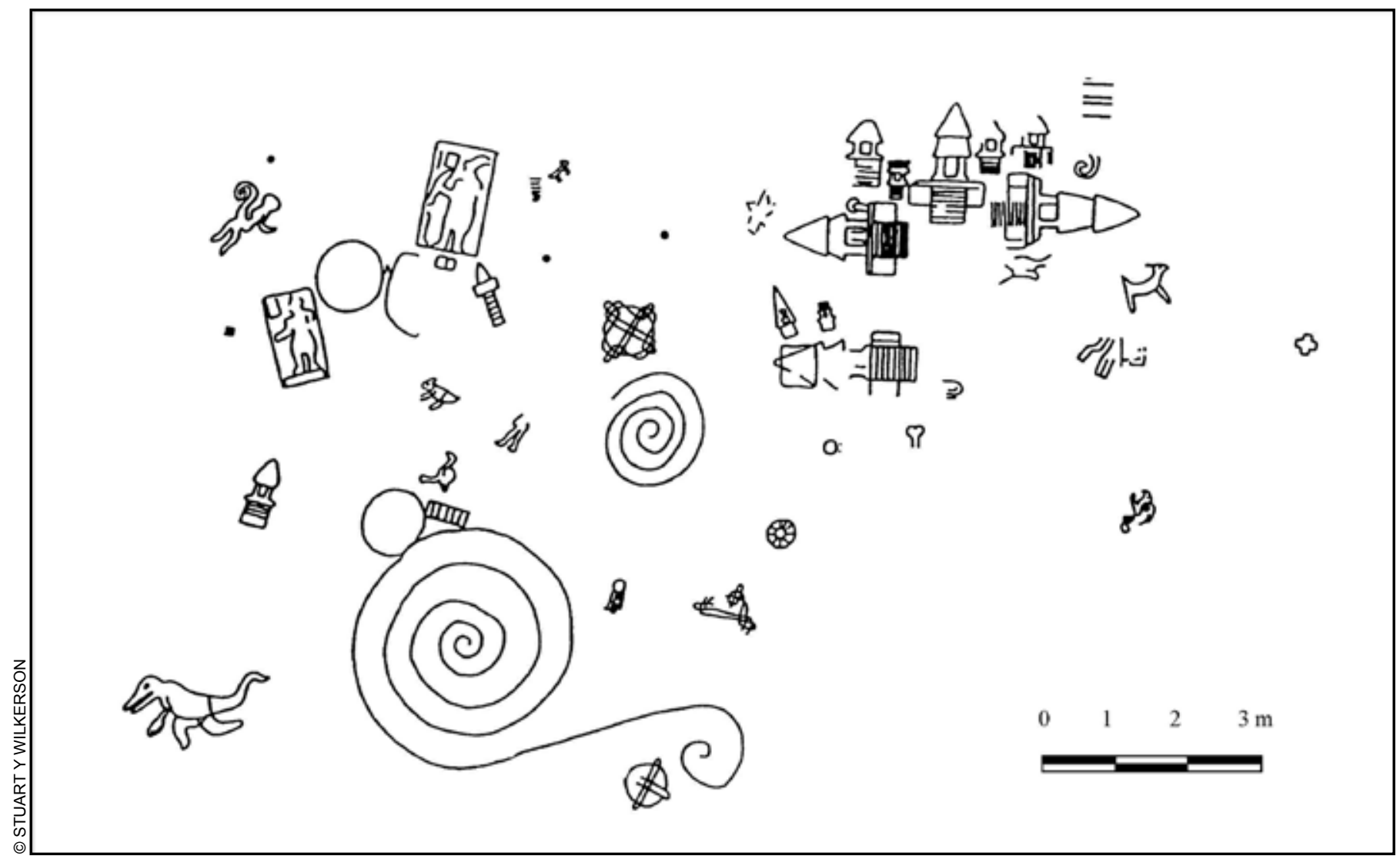

Parte de los grabados rupestres del sitio Planchón de las Figuras, Estado Chiapas, México (copia modificada de Stuart y Wilkerson 1995, lámina 2). 
de Puuc (Estado Yucatán, México). Dentro de este proyecto documentó también el arte rupestre de dos cuevas. Rissolo (Universidad de California Riverside) analizó la situación arqueológica de cuevas decoradas en la región Yalahau en el norte del Estado Quintana Roo (México). Awe y Helmke (University College London) investigaron iconografías rupestres en las cuevas del Distrito Toledo (Belice).

En las serranías orientales de El Salvador los arqueólogos Coladan (Universidad Nacional, Costa Rica) y Amaroli documentaron las relaciones entre representaciones rupestres y sus contextos arqueológicos. Las únicas investigaciones nuevas del arte rupestre que se conocen de Honduras vienen de la historiadora de arte McKittrick.

Navarro (Museo Nacional de Nicaragua), Baker (Proyecto Arqueológico Ometepe) y Espinoza (Universidad Nacional de Nicaragua) documentaron sitios rupestres de la zona Pacífica de Nicaragua. Mientras que Navarro (1996) buscó relaciones entre la situación ecológica y el estilo de representaciones rupestres, Baker se concentró en la documentación sistemática de los petroglifos de la isla Ometepe. En la documentación del arte rupestre del Archipiélago de Solentiname trabajaron Di Cosimo y Laurencich Minelli (Centro Italiano de Estudio e Investigación Arqueológica Precolombina).

En Costa Rica Hardy (University of California Los Angeles) y Vázquez (Museo Nacional de Costa Rica) documentaron grabados rupestres del sitio Pedregal (Provincia Guanacaste). La arqueóloga Blanco (Universidad Nacional) organizó en la región del Pacífico Sur proyectos estudiantiles de documentación. Künne (Museo Antropológico de Berlín) investigó representaciones rupestres en el Valle de El General (Costa Rica) y en la Provincia Chiriquí (Panamá). Aplicó un sistema digital de documentación (Trigomat) que permite dibujos tridimensionales de rocas grabadas (2003: 245-247, figs. 24-26).

El arte rupestre de la región occidental de Panamá fue estudiado por los antropólogos Joly Adames (Universidad Autónoma del Chiriquí) y Quintero Sánchez (Associación Cultural Ngöbe).

Los resúmenes regionales de arte rupestre de México Oriental y Centroamérica contenidos en este libro reflejan

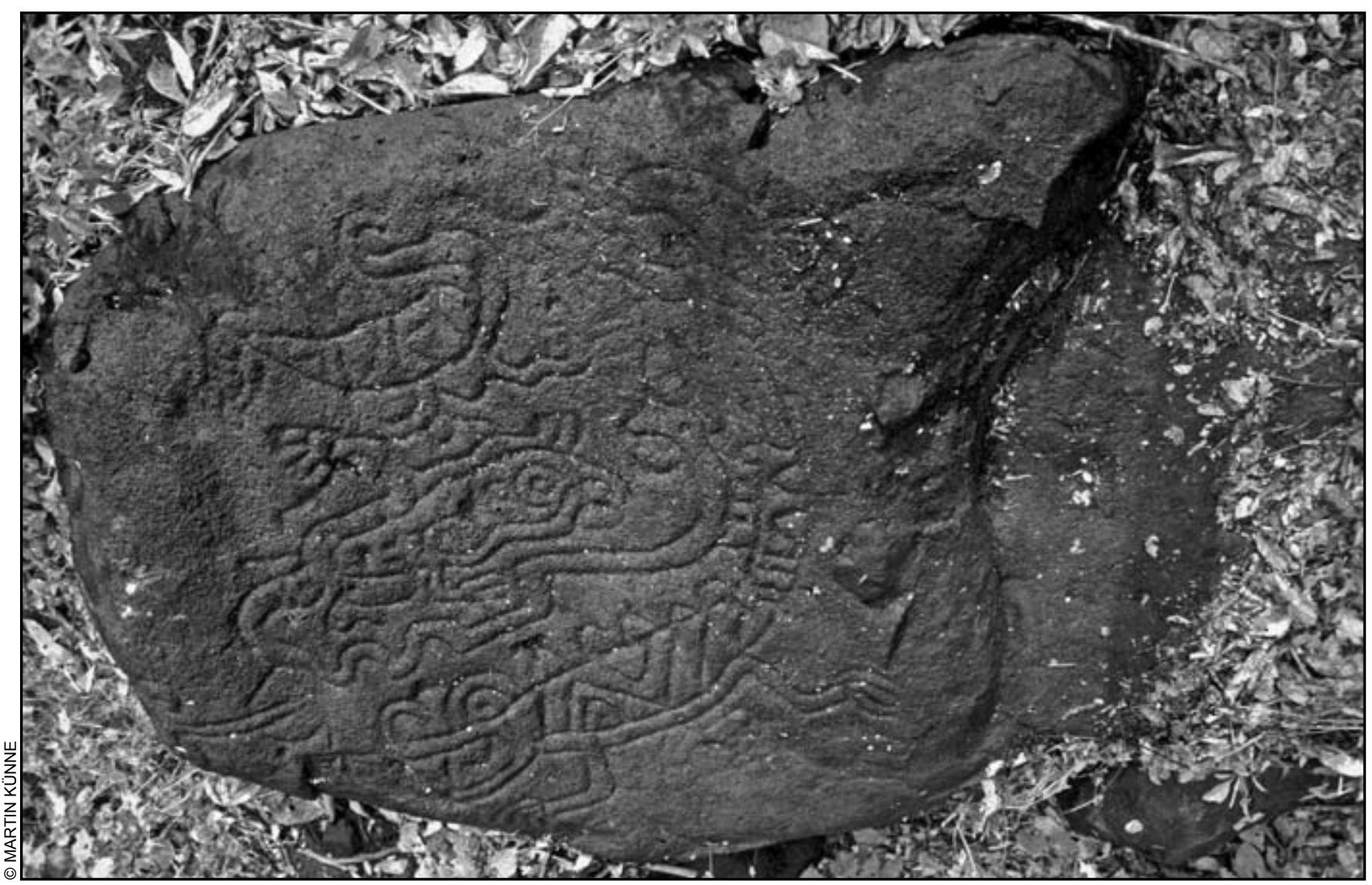

Piedra volcánica con motivos zoomorfos de la isla Ometepe, territorio Maderas, cerca del sitio Los Cuchillos (N-RIO-48). 
el estado actual del registro y de la documentación en esos países. Tratamos de ofrecer una introducción al tema e ilustraciones que representen los diversos conjuntos iconográficos existentes, sin poder presentar todas las diversas modalidades estilísticas. Evitamos incluir en las ilustraciones fotos de grabados tizados para no divulgar este método dañino de marcar el arte rupestre (ver Bednarik 1990). De la misma manera, quisiéramos advertir sobre la práctica negativa para la preservación del arte rupestre de humedecer las pinturas rupestres (Bednarik 1994) y algunas normas necesarias para regularizar el sacado de muestras (Bednarik 1992, Dorn 1992). Estas normas ya han sido adoptadas internacionalmente, tanto en los Códigos de Etica de organizaciones regionales, por ejemplo por ARARA en Norteamérica y SIARB en Sudamérica, como en el Código de Etica de IFRAO, la Federación Internacional de Organizaciones de Arte Rupestre (publicado en la revista Rock Art Research 17/2: 157-159, Melbourne 2000).

Una de las tareas principales del investigador de arte rupestre es elaborar registros y documentaciones sistemáticos que formen la base para la clasificación de los sitios y sus elementos, su interpretación y la planificación de medidas de preservación. Mientras en los inicios de la investigación de representaciones rupestres, muchas veces se presentaron registros parciales, dando énfasis a ciertos elementos seleccionados que parecían particularmente significativos para una interpretación (que por ende resultó arbitraria y dudosa), ahora predominan en los programas de investigación los esfuerzos por documentar el corpus completo de todos los motivos, lo que permite evaluarlo en su contexto. Debido a las características del sitio y sus manifestaciones, además según los objetivos del proyecto específico, pueden variar las técnicas de registro utilizadas. Existen métodos simples para la documentación de elementos iconográficos aparte de tecnologías de punta que permiten, por ejemplo, la digitalización de las imágenes y una alta exactitud de las reproducciones (ver Taboada y Strecker 2002).

Para la reproducción fotográfica del arte recomendamos incluir una escala de tamaño, como la escala IFRAO (Bednarik 1996), mientras los dibujos deberían incluir en lo posible una escala de tamaño, escala de colores en los casos de pinturas y una flecha indicando la dirección norte, lo que permite deducir la orientación del panel.

\section{Clasificaciones}

Se puede clasificar las representaciones iconográficas según la tecnología de su ejecución o según sus características estilísticas (formas y diseños). Los editores del libro entienden como arte rupestre representaciones iconográficas que se encuentran en piedras naturales, en rocas, en farallones o en estalagtitas, estalagnitas, columnas, paredes y techos rocosos. Pueden ser el resultado de la ejecución de una sola técnica (pinturas rupestres o grabados rupestres) o de la combinación de diferentes modos de manufactura (grabados pintados). Las representaciones rupestres pueden perdurar por mucho tiempo o solo durante un tiempo limitado. Pueden encontrarse en objetos inmuebles (arte parietal) o en objetos de carácter mobiliar. Nunca modifican completamente la forma natural del objeto decorado distinguiéndose de esta manera del arte plástico. Las representaciones rupestres pueden encontrarse en espacios subterráneos de cuevas o al aire libre (piedras, rocas, acantillados, aleros).

Para entender mejor a los productores de representaciones rupestres y el uso de sus manifestaciones iconográficas, la investigación debería tomar en cuenta no solamente las características estilísticas del arte rupestre, sino también las técnicas de su producción. En el caso de los grabados, resultado de una extracción de material de la superficie rocosa, se puede tratar de motivos profundamente grabados creando una especie de relieve, mientras otros fueron incisos ligeramente, etc. Las "cúpulas" o "tacitas", depresiones redondas artificiales, pueden ser el producto de golpeteo, abrasión $u$ otras técnicas.

A veces, los diferentes modos de manufactura implican indicaciones de un uso social específico, por ejemplo, cuando se eligieron técnicas particulares para representar ciertos motivos o para decorar superficies rocosas en lugares determinados como caminos, áreas de descanso, ríos, etc. La utilización de diferentes técnicas puede indicar a veces la posición cronológica de las representaciones encontradas en superposición. Dubelaar (1986, cap. III: 16-22) publicó una introducción útil a la problemática de la manufactura de grabados rupestres. Se necesitaría experimentos controlados de réplicas (por supuesto, en piedras pequeñas del mismo material rocoso como las manifestaciones rupestres) para entender mejor la manera de producción del arte rupestre y los diferentes estilos y sus técnicas.

Según el estilo de la imagen, se pueden reconocer representaciones abstractas (geométricas, no representativas), estilizadas (formales) y realistas (naturalistas, representativas). Según el contenido iconográfico de la imagen se diferencia usualmente entre representaciones geométricas, antropomorfas, zoomorfas, fítomorfas, biomorfas y motivos de fuentes arqueológicas (objetos, estructuras arquitectónicas). 
A pesar de la semejanza de algunos motivos con seres naturales o con objetos determinados, no sabemos si los artistas realmente querían representar tales seres u objetos o si intentaron representar seres transcendentes, conceptos culturales o apariciones entópticas. En la descripción y clasificación de los motivos, es recomendable utilizar términos generales como elemento antropomorfo, zoomorfo y fitomorfo, que no impliquen una identificación o interpretación,. Las representaciones rupestres pueden ser accesibles para un amplio público o tener una visibilidad restringida. En la mayoría de los casos no se puede decidir si representan la obra de artesanos especializados o de personas no especializadas.

A causa de la multitud de los enfoques de investigación falta una terminología estandarizada y generalmente aceptada de clasificación. Aunque la denominación "arte rupestre" implica una función individual y estética de iconografías prehistóricas, hay que considerar que tanto la concepción de individuos autónomos como la diferenciación entre lo privado y lo público, entre lo mágico y lo real, entre lo secular y lo profano o entre la decoración y el objeto decorado son invenciones del esclarecimiento europeo que probablemente no reflejan las categorías del pensamiento de sus creadores. Por ejemplo, algunos grupos indígenas de Baja América Central no distinguen entre esculturas de piedra, piedras grabadas y piedras naturales con formas especiales. La falta de denominaciones particulares dentro de su lengua indica la relatividad de cada sistema de clasificación. Los editores renunciaron por eso a una unificación clasificatoria de los términos utilizados por los diferentes autores.

\section{Archivos y foros de intercambio de información}

El estado de registro e investigación del arte rupestre difiere de país a país. Parece más avanzado en México, Guatemala y Nicaragua que en Panamá, Honduras y Belice. Dos de los archivos más grandes que coleccionan documentaciones del arte rupestre a nivel mundial se encuentran en Los Estados Unidos de América (UCLA Rock Art Archive, The Coetsen Institute of Archaeology of UCLA, A 210 Fowler Museum, 151006, University of California Los Angeles, California 90095-1510, URL: http://www.sscnet.ucla.edu/ioa/rockart/ index.htm) y en Italia (World Archive of Rock Art, Centro Camuno di Studi Preistorici, I-25044 Capo di Monte, Val Camonica, Brescia, URL en configuración: http:// www.ccsp.it). Las instituciones científicas de los países

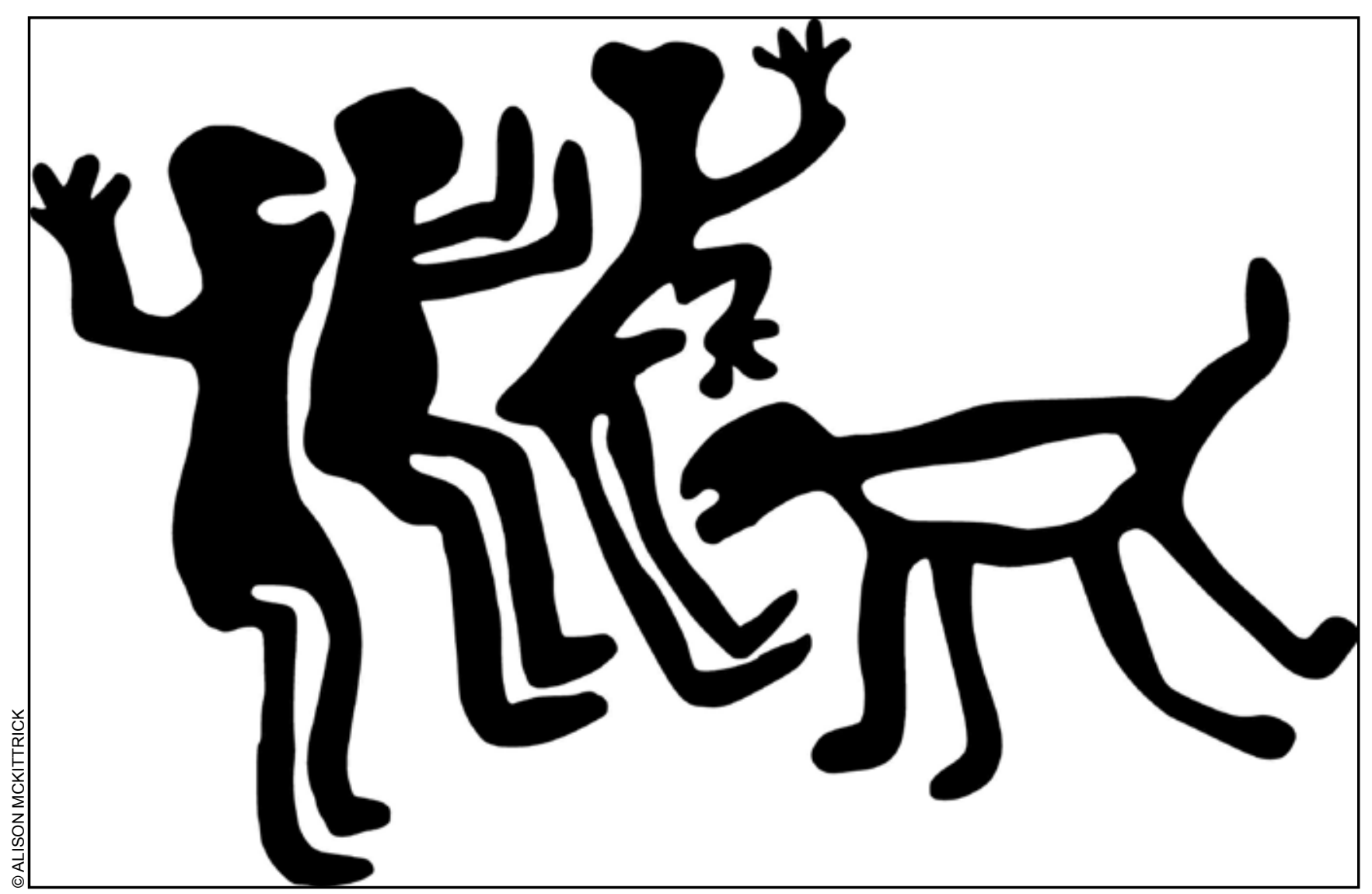

Pinturas blancas de tres antropomorfos y un animal, Cueva La Pintada de Azacualpa, Departamento de La Paz, Honduras. 
centroamericanos tienen a menudo solo documentaciones limitadas. Esta situación dificulta el acceso al material existente aunque algunos investigadores dejaron copias de sus documentaciones en los países donde realizaron sus investigaciones.

Otras fuentes de información son el "Bancroft Rock Art Database" (URL: http://www.bancroft.berkeley.edu/ collections/rockart/html), el "arterupestre/web" (URL: http://www.rupestreweb.info/) y el "RockArtNet" (URL: http://www.rupestre.net/rockart/). El "Bancroft Rock Art Database" comprende más de 16.000 citaciones bibliográficas del arte rupestre de muchas partes del mundo. El "RockArtNet" incluye una multitud de conexiones a páginas Web. El "arterupestre/web" presenta además un foro de discusión entre especialistas, aficionados y estudiantes de representaciones rupestres (rupestreweb@yahoogroups. com). La página Web de la revista Mexicon (URL: http:// www.mexicon.de) contiene a veces también artículos y noticias del arte rupestre de México y América Central.

Asociaciones y fundaciones que muestran interés en investigaciones del arte rupestre de nuestra área de estudio son la Federación Internacional de Organizaciones de Arte Rupestre (IFRAO: URL: http://www.cesmap.it/ifrao/ifrao. html y http://mc2.vicnet.net.au/home/ifrao/web/index. html), la Sociedad de Investigación del Arte Rupestre de Bolivia (SIARB, Casilla 3091, La Paz, Bolivia; URL: http:// www.siarbbolivia.org), la "Foundation of the Advancement of Mesoamerican Studies" (FAMSI, 268 South Suncoast Boulevard, Crystal River, Florida 34429; URL: http://www. famsi.org/), la "Bradshaw Foundation" (URL: http://www. bradshaw foundation.com/) y el "Viking Fund/Wenner-Gren Foundation" (Wenner-Gren Foundation for Anthropological Research, Inc., 220 Fifth Avenue, 16th Floor, New York, NY 10001-7708; URL: http:/www.wennergren.org/). Las tres últimas fundaciones concedieron becas para proyectos de documentación sistemática y contextual. La SIARB publica un boletín anual (http://www.siarb-bolivia.org/esp/principal. htm) que incluye textos sobre el arte rupestre de México y América Central (ver también lista de publicaciones: URL: http://rupestreweb.tripod.com/bosiarb.html).

Entre las instituciones que intensificaron la documentación de representaciones rupestres durante los años pasados se encuentran el "Council for the Archaeology of Subaquatic

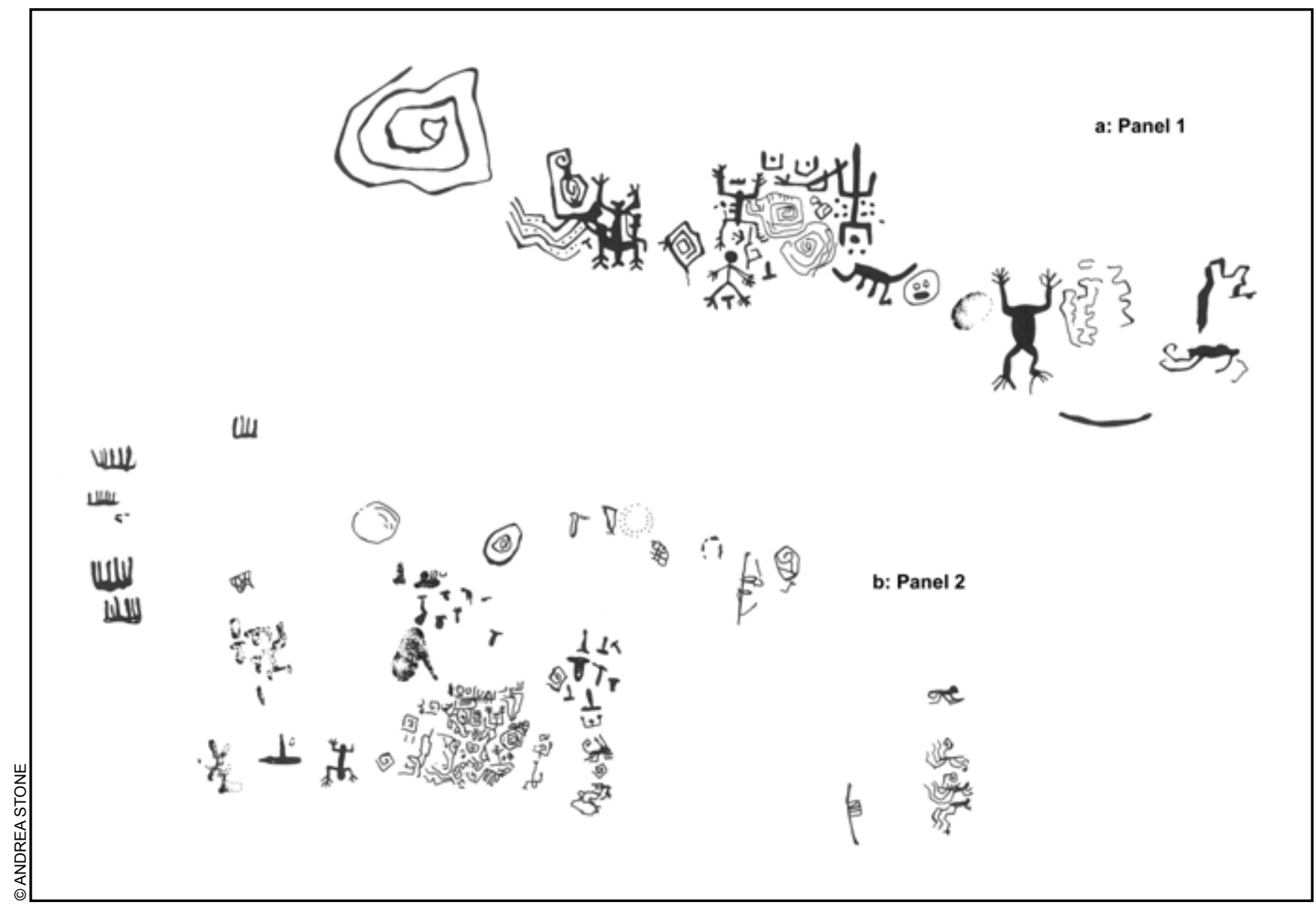

Arte rupestre de la cueva Actun Dzib, Belice. Dibujos de Christophe Helmke, basados en dibujos de Andrea Stone (1995). 
Caves" (CASC, México) Consejo Nacional para la Cultura y el Arte (CONCULTURA), Departamento de Arqueología, El Salvador; el Instituto Hondureño de Antropología e Historia (IHAH), Departamento de Antropología (DIA), Honduras y el Museo Popol Vuh, Guatemala. Iniciativas que promovieron proyectos de arte rupestre son el "Council for the Archaeology of Subaquatic Caves" (CASC, México), el "Mesoamerican Cave Archaeology Network" (MCAN, México/EE.UU.), el "Western Belize Regional Cave Project" (Belice/EE.UU.), la "Fundación Barú" (Panamá) o "Piedras Vivas" (Costa Rica/Alemania/Suiza). El Museo Popol Vuh (Ciudad de Guatemala, Universidad Francisco Marroquín, Campus Central, zona 10, $6^{\mathrm{a}}$ calle) organiza desde el año 2000 coloquios anuales sobre arte rupestre de Guatemala. "El Council for the Archaeology of Subaquatic Caves" (CASC) invitó en el año 2002 al "Primer Congreso de Arqueología Subacuática y Espeleologica" que se realizó en la Universidad Autónoma de Yucatán (UADY) y en el Centro Ecológico de Akumal (Quintana Roo, México). El "Mesoamerican Cave Archaeology Network" (http://www. mesocave.org/) y el "Western Belize Regional Cave Project" (http://www.indiana.edu/ belize/) representan asociaciones internacionales de científicos quienes se dedican a la documentación sistemática de paisajes prehistoricos desde perspectivas multidisciplinarias.

Al contrario la "Fundación Barú" (Panamá) y "Piedras Vivas" son más bien iniciativas locales. En el año 2001 organizaron en David (Panamá) el "Primer Curso Universitario de Arte Rupestre" de América Central.

\section{Conservación}

Los métodos de documentación e interpretación cambian continuamente llegando a registros más sofisticados. Sin embargo, el objetivo principal de la investigación debería ser la preservación de los objetos de estudio. La deforestación, cultivación y urbanización de grandes territorios baldíos e indígenas amplió considerablemente los espacios de utilización social durante las cinco décadas pasadas en los países centroamericanos.

Como resultado muchas representaciones rupestres de la región se encuentran hoy en zonas de utilización cotidiana. Aunque muchas veces se evita la publicación de informaciones detalladas sobre la localización de sitios rupestres, ahora están afectados a menudo por vandalismo, como rascado y pintura moderna. Tampoco los complejos iconográficos que se encuentran en lugares alejados (por ejemplo, Cueva Jolja' y Cueva de Yaleltsemen en Chiapas) o en cierta manera protegidos (Naj Tunich en Guatemala) están seguros de actividades destructivas. Por eso es necesario hacer un esfuerzo mayor para lograr estrategias de conservación del arte rupestre.

Los nuevos conceptos de protección tratan de vincular la conservación de representaciones rupestres con el creciente turismo ecológico, con proyectos de información pública y con la formación de especialistas. A nivel internacional, ya existe un amplio acuerdo sobre la necesidad de evitar métodos dañinos en la documentación del arte rupestre que podrían poner en peligro la preservación de este patrimonio, como demuestra el "Código de Ética" de IFRAO, de la "Federación Internacional de Organizaciones de Arte Rupestre" (publicado en la revista Rock Art Research, 17(2):157-159, Melbourne, noviembre 2000). A nivel regional y local existen iniciativas que se dedican a habilitar el acceso a sitios rupestres elegidos; instalan letreros o cédulas de información, publican folletos o se preocupan de la formación de guarda ruinas y guías turísticos. En muchos países del mundo se entiende hoy a las representaciones rupestres como parte integrante del patrimonio cultural.

La lista de sitios del "Patrimonio Cultural de la Humanidad" de la UNESCO (URL:http://whc.unesco.org/pg.cfm?cid=31) incluye también lugares con represen-taciones rupestres en América Central: la Reserva de Biosfera Río Plátano en Honduras; el Parque Nacional La Amistad en Costa Rica y en Panamá. Algunos sitios con arte rupestre de América Central están protegidos además por leyes nacionales que los declaran como "Patrimonio Cultural" (Cerro Valério/Sta. Lucía, Panamá; Cailagua, Nicaragua) o como "Monumento Histórico" (El Farrallón en Sandillal, Costa Rica; Cueva del Espírito Santo, El Salvador). En el año 2002 la Asamblea Nacional de Panamá aprobó una revisión de la Ley No. 19 del 9 de octubre de 1984 y declaró a todos los lugares con grabados rupestres en el país como sitios de "Patrimonio Histórico".

Sin embargo la conservación de representaciones rupestres no solo es una cuestión técnica y jurídica. Exige también una nueva práctica social. Sin la participación directa o indirecta de la población local en la redefinición funcional de los sitios con arte rupestre, estos vecinos no se interesarán en las medidas necesarias para su protección. Muchas poblaciones indígenas en las Américas mantienen tradiciones y derechos propios sobre lugares con arte rupestre que difieren de los conceptos de utilización de otros sectores sociales. Sin embargo, aunque los escasos testimonios arqueológicos de la prehistoria de la humanidad no son propiedad de las actuales generaciones ni de grupos particulares, son nuestras ideas y acciones las que deciden sobre su permanencia o desaparición futura. 


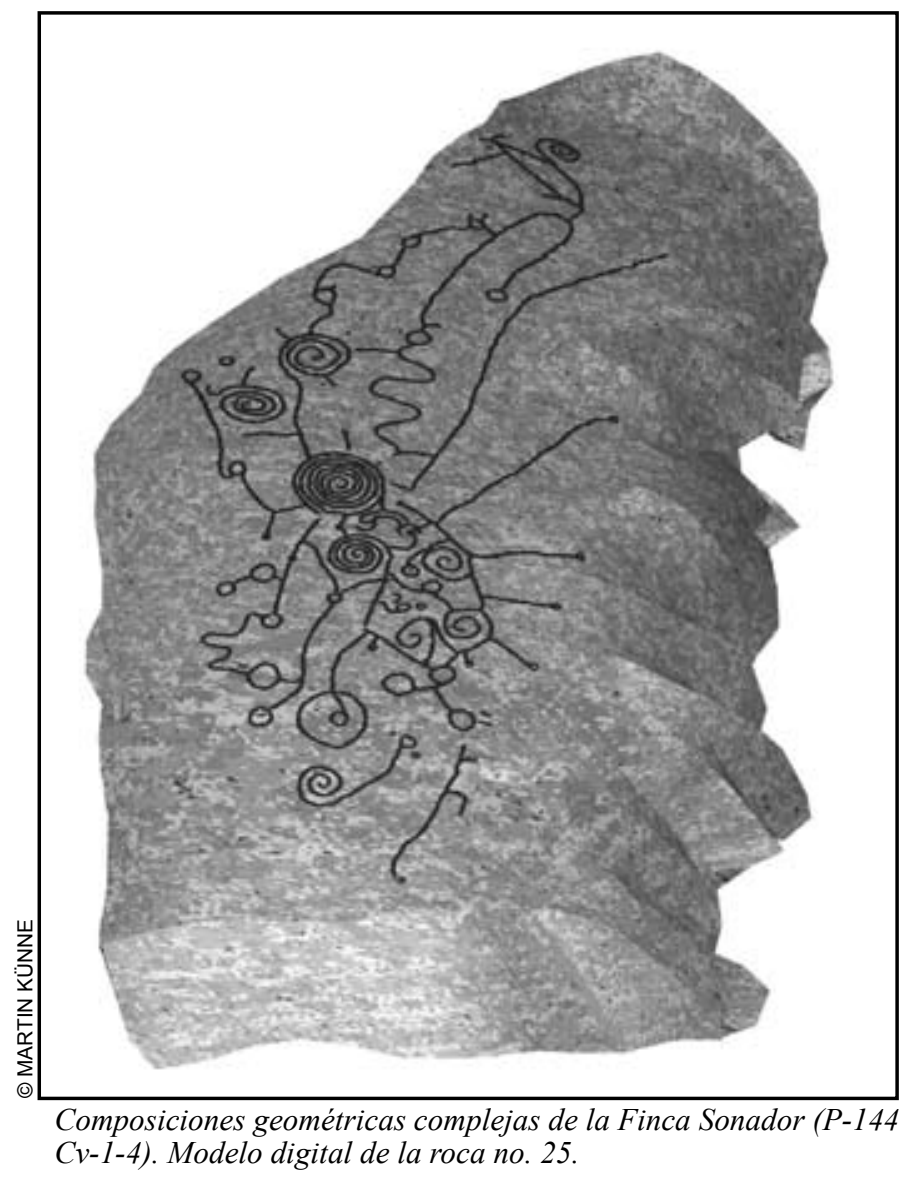

12. Los textos de este libro

Todos los artículos se basan en investigaciones sistemáticas de los autores y sus equipos de trabajo. Reflejan tanto sus intereses y enfoques particulares como la heterogeneidad arqueológica en los diferentes países. A menudo estos aportes ofrecen por primera vez una visión del conjunto del arte rupestre en esas regiones. Incluyen una descripción geográfica del área de estudio, un resumen de las investigaciones anteriores, una caracterización iconográfica de las representaciones documentadas, informaciones sobre su situación arqueológica y datos sobre el estado de su preservación. Cada artículo comprende además un mapa que muestra la distribución geográfica de los sitios más conocidos.

El panorama multifacético del arte rupestre de los estados Chiapas y Tabasco (México) comprende los grabados y pinturas que dejaron las sociedades mayas, los relieves del horizonte olmeca y testimonios iconográficos de diferente procedencia. Las 110 rocas grabadas de la Finca Las Palmas representan uno de los sitios más extensos, que fue documentado en forma completa por Weber y Strecker en los años 70 del siglo pasado. Mientras en Chiapas existen por lo menos 69 sitios con representaciones rupestres (Pincemin 1999b), incluyendo también el sitio con la inscripción más antigua de toda América Central (Cueva Jolja'), de Tabasco se tiene solo informaciones iniciales. A pesar de la gran variedad de estas manifestaciones, la mayor parte de los sitios en ambos estados carece de documentaciones sistemáticas y falta una protección efectiva.

Las documentaciones del arte rupestre de los estados Yucatán y Campeche (México) se vinculan en primer plano con la región Puuc, la cual contiene la concentración más grande de cuevas decoradas de toda América Central. Algunos sitios como la cueva de Loltun ya han sido investigados desde la mitad del siglo XIX, sin embargo, en muchos casos los registros del arte rupestre se limitan a informes parciales. Del estado de Campeche se han publicado solamente dos sitios. M. Strecker y A. Stone subrayan la asociación de sitios decorados con lugares subterráneos y fuentes de agua. Informan sobre una gran variedad iconográfica que se relaciona principalmente al período Clásico. Mientras que la cueva Acum contiene la mayor cantidad conocida de improntas de manos, en la cueva Dzibichen se encuentra el corpus más extenso de imágenes coloniales. La cueva Miramar (Campeche) representa uno de los sitios raros que están directamente asociados con estructuras de arquitectura monumental.

Rissolo investigó dentro de un proyecto de largo plazo las características y las dimensiones del uso de las cuevas de la región Yalahau que se encuentra en el norte del estado Quintana Roo (México). Su aporte describe los grabados y pinturas rupestres de 16 sitios subterráneos. Analiza tanto sus relaciones iconográficas como su situación regional y arqueológica. Presta atención especial a las representaciones rupestres de la cueva Pak Ch'en. La vinculación de los sitios investigados con las estructuras arqueológicas de la superfície queda para investigaciones futuras como también la documentación del arte rupestre de la región sur del estado Quintana Roo.

De Belice se conocen al presente solo 15 sitios con arte rupestre, los cuales se encuentran exclusivamente dentro de cuevas al borde de las Montañas Mayas. No se sabe de representaciones del arte elitista ni de textos jeroglíficos, pero las representaciones documentadas incluyen una gran variedad de técnicas de producción. A diferencia de otros autores, Helmke, Awe y Griffith clasifican también esculturas toscas que se encuentran dentro de estructuras subterráneas como manifestaciones de arte rupestre. Incluso mencionan el único ejemplar de una escultura de arcilla registrada en una cueva maya. De esta manera promueven una nueva 
discusión sobre la separación entre representaciones iconográficas del arte parietal y de otros estructuras u objetos que se encuentren en los mismos contextos arqueológicos. Los autores analizan la distribución geográfica del arte rupestre del país en relación a la composición geológica de sus paisajes naturales. Según la cantidad de las técnicas aplicadas y las iconografías documentadas, distinguen tres sub-áreas coherentes, que interpretan como posibles indicadores de diferentes regiones de interacción política.

Las representaciones rupestres de Guatemala están caracterizadas por A. Stone según su situación contextual dentro de la región montañosa o dentro de las vastas llanuras tropicales del país. Mientras que en el Petén guatemalteco se documentaron 19 sitios subterráneos, las representaciones de las serranías se encuentran principalmente en sitios al aire libre. Aunque los primeros informes ya proceden de la mitad del siglo XIX, no se desarrollaron investigaciones sistemáticas antes del año 1970. Hoy se conocen aproximadamente 60 sitios con grabados y pinturas rupestres que incluyen representaciones de las culturas mayas del Clásico Tardío, de grupos del horizonte olmeca y de la cultura de Cozumalhuapa. Unas representaciones están acompañadas por inscripciones jeroglíficas. En la cueva Naj Tunich A. Stone documentó 89 complejos iconográficos para los cuales trata de mostrar posibles funciones sociales. Aparte de resumir detalladamente los sitios rupestres y sus estilos iconográficos, también informa sobre la aplicación de nuevos métodos tecnológicos de documentación. Poco antes de terminar la edición de este libro nos llegó la noticia sobre el primer fechamiento de una pintura rupestre de Guatemala (publicada en la revista $\mathrm{U}$ tz' $\mathrm{ib}$, 3(3): 26, Guatemala, diciembre 2002), logrado a través de la cooperación recibida de parte del Depto. de Química de la Universidad Texas A\&M. El equipo dirigido por Marvin Rowe logró el fechamiento de la pintura conocida como El Diablo Rojo (Cerro de la Mariposa, Amatititlán). De iconografía olmeca, la pintura contaba con dos capas, la inferior de color negro, hecha con carbón, permitió el fechamiento límite más antiguo, de 3030+45 años a.p. (CAMS 88192); la capa superior, que es la que aún se observa en la superficie y en la que se usó óxido de hierro, no presentó suficiente material orgánico para su fechamiento. Lo interesante de este dato es que, pese al difícil acceso de la pintura, ambas capas nos indican que la misma fue originalmente negra y no roja como se ve en la actualidad y que fue retocada, presuntamente en tiempos prehispánicos.

Coladan y Amaroli investigaron en la década de los 90 del siglo pasado los sitios con grabados y pinturas rupestres del oriente y de las regiones centrales de El Salvador. Su texto da a conocer por primera vez en forma coherente el arte rupestre salvadoreño -después de más de 30 años de silencio. Incluye

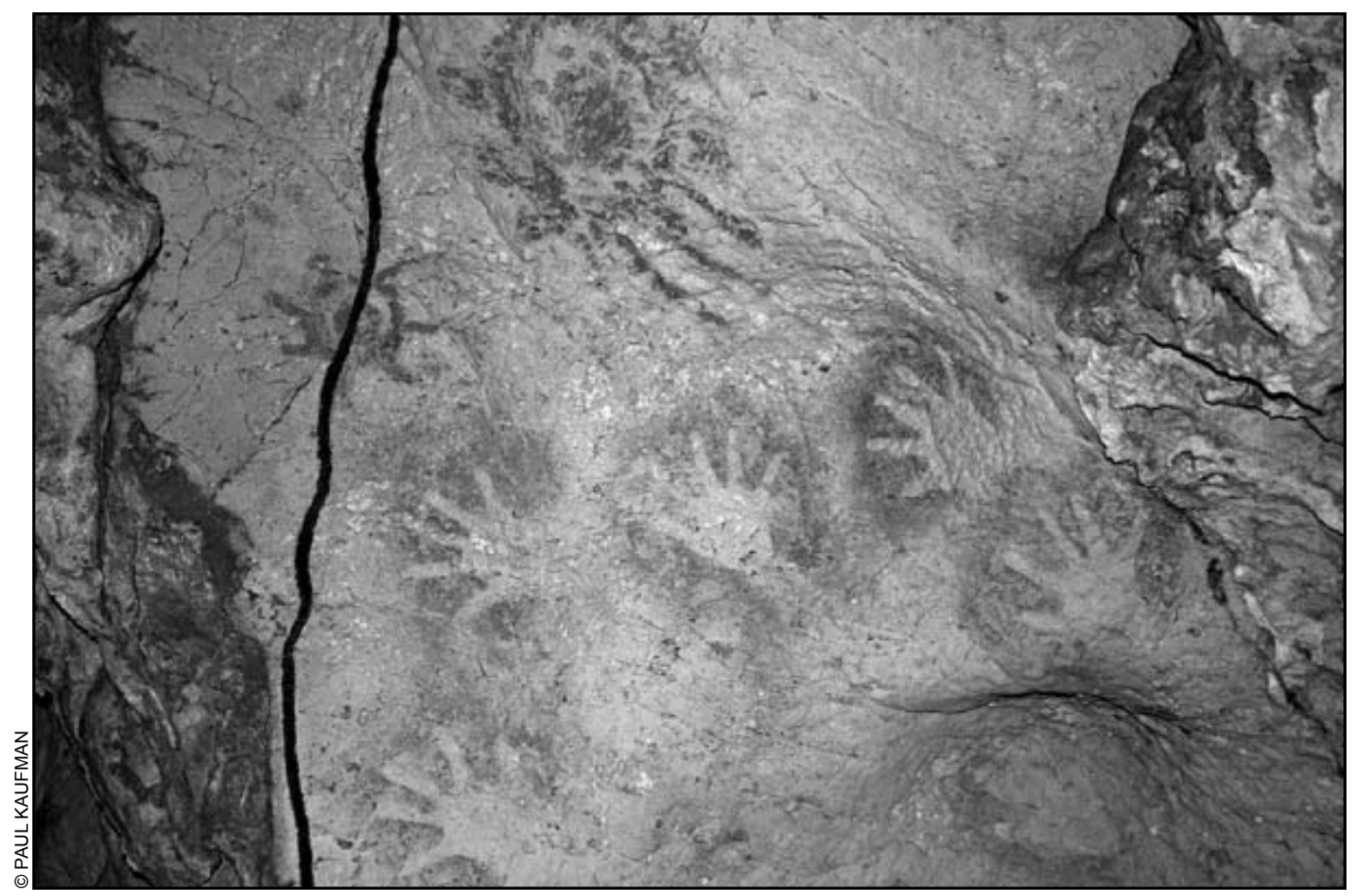

Improntas de manos negativos y pinturas geometricas en la Cueva La Conga, Departamento de Jinotega, Nicaragua. 
muchos sitios con representaciones de origen no maya que fueron documentados por la primera vez. Los autores indican las relaciones entre representaciones rupestres, situaciones topográficas y contextos arqueológicos concentrándose en la reinvestigación sistemática de la Cueva del Espíritu Santo. Subrayan la necesidad de encontrar asociaciones directas entre representaciones rupestres y contextos arqueológicos para determinar la antigüedad de estas manifestaciones.

El arte rupestre de Honduras comprende todas las variedades iconográficas de América Central. Mientras que algunas representaciones se vinculan claramente con influencias de Alta América Central, otras imágenes muestran fuertes relaciones con tradiciones de origen sureño. Los complejos iconográficos consisten principalmente en grabados rupestres que están situados al aire libre, así como también las raras pinturas conocidas. Aunque ya se registraron aproximadamente 50 sitios, solo se tiene muy pocas informaciones sobre su situación contextual, lo cual dificulta su asociación cronológica. El aporte de McKittrick se basa en documentaciones iconográficas que la autora realizó entre 1993 y 1995 en 13 sitios de las regiones centrales y orientales del país. Se concentra en la investigación de la Cueva Pintada, la cual contiene el corpus más diverso del arte rupestre hondureño.

Nicaragua tiene una tradición rica de investigación de su arte rupestre, pero las documentaciones sistemáticas se limitan a la región Pacífica. Existen tanto grabados como pinturas y grabados pintados. Grabados rupestres se encuentran también en otras partes del país. El texto de Baker se basa en investigaciones que la autora realiza desde el comienzo de los años 90 del siglo XX en la isla Ometepe. Mientras que aquí aparecen varias representaciones figurativas, la mayor parte del arte rupestre nicaragüense consiste en diseños abstractos para los cuales la autora distingue dos niveles de complejidad. Baker supone que las imágenes conocidas son producto de artesanos no especializados e indica las dificultades de un análisis funcional y cronológico profundo. La autora reclama la aplicación de teorías modernas de interpretación y subraya la necesidad de investigaciones antropológicas.

El arte rupestre de Costa Rica se concentra en las regiones montañosas del país y consiste principalmente en grabados rupestres que muestran motivos abstractos. Su mayoría se encuentra en zonas sin contextos de asentamientos antiguos, sin embargo se conocen representaciones rupestres de antiguas rutas de intercambio cultural, de cementerios y de centros políticos. En algunos casos se documentaron relaciones directas a estructuras arquitectónicas. Aunque las iconografías muestran una gran homogeneidad se puede suponer tres regiones estilísticas que se vinculan con las principales regiones culturales del país. El artículo se basa en investigaciones que Künne realizó entre 1995 y 2000 en la región del Pacífico Sur.

En Panamá todavía no se han hallado pinturas rupestres, a diferencia de todos los demás países de América Central. Los sitios reportados consisten exclusivamente en profundos grabados rupestres en rocas volcánicas que muestran principalmente motivos abstractos. Los complejos documentados se encuentran en su mayor parte en las cordilleras y llanuras Pacíficas de las regiones orientales y centrales del país dejando toda la región Atlántica fuera del foco de investigación. El texto se basa en prospecciones que Künne realizó en 1998 y en 2001 en la Provincia Chiriquí y en los materiales de la documentación de los Hartes (1952-59, $1961 \mathrm{a}, \mathrm{b})$ de la mitad del siglo pasado. Hasta hoy la escasez de documentaciones contextuales y de investigaciones modernas complica un análisis profundo del arte rupestre panameño.

Esperamos que este compendio sirva para iniciar en toda la región del oriente de México y América Central nuevas investigaciones ampliando tanto la base material de documentación como los enfoques de interpretación de las representaciones rupestres.

\section{Referencias}

Al final de este libro, se presentan todas las referencias a publicaciones que se refieren directamente al arte rupestre del oriente de México y América Central; están ordenadas tanto en orden regional como en orden alfabético. Los títulos que contienen informaciones generales, no vinculados directamente con representaciones rupestres de nuestra región de estudio, aparecen bajo la sección Obras Generales.

\section{Agradecimientos}

Agradecemos a todos los autores que colaboraron en los esfuerzos de producción de este libro. En particular quisiéramos expresar nuestro profundo agradecimiento a Andrea Stone quien organizó la sesión de Arte Rupestre en la 66a Reunión Anual de la "Society for American Archaeology" (SAA), encuentro que nos dio la oportunidad de pedir la colaboración de algunos de sus participantes. Agradecemos además a los dos revisores del libro, Gerhard Baer y Heiko Prümers, cuya lectura crítica y sugerencias constructivas nos ayudaron a editar los textos. 


\section{Bibliografía, introducción}

Armitage, Ruth A.; James Brady; Allan Cobb; John R. Southon y Marvin W. Rowe 2001 "Mass spectrometric radiocarbon dates from three rock paintings of known age". En: American Antiquity, 66(3): 471-480. Washington, D.C.

Bahn; Paul y Angelo Fossati (eds.):

1996 Rock Art Studies: News of the World, 1. Oxford, UK: Oxbow Books.

Baudez, Claude F.

1970 Mittelamerika. Nagel Verlag, München, Genf, Paris.

Bednarik, Robert G.

1990 Sobre la prácticar de tizar los petroglifos. En: Boletín SIARB 4: 24-26, La Paz, Bolivia.

1992 Código de ética para sacar muestras. En: Boletín SIARB 6: 22-23, La Paz, Bolivia.

1994 Reflexiones sobre la práctica de humedecer las pinturas rupestres. En: Boletín SIARB, 8: 28-29, La Paz, Bolivia.

1996 La calibración computarizada a color en las fotografias de arte rupestre. En: Boletín SIARB, 10: 24-27, La Paz, Bolivia.

2001 Rock art science. The scientific study of paleoart. Brepols, Turnhout, Bélgica.

Chippindale, Christopher

2001 Studying ancient pictures as pictures. En: Whitley, David (ed.): Handbook of rock art research, pp. $247-272$. Altamira Press, Lanham, New York, Oxford, Walnut Creek, California.

Dorn, Ronald I.

1992 Discusión sobre la ética de muestreo de petroglifos para su datación. En: Boletín SIARB, 6: 23, La Paz, Bolivia.

Dubelaar, Cornelis Nicolaas

1986 South American and Caribbean petroglyphs. Foris Publications, Dordrecht, Holanda; Riverton, New Jersey.

Haberland, Wolfgang

1959 Zentral-Amerika: Begriff, Grenzen und Probleme. En: Mitteilungen aus dem Museum für Völkerkunde in Hamburg, XXV: 53-59. Hamburg.

Harte, Neville A.

1952- Site index cards. Museo de Historia y de Arte José Obaldía. Archivo de la Fundación

1959 Cultural Gallegos. David, Panamá.

1961a Panorama of Panama Petroglyphs. Panamá.

1961b Petroglyphs of Panama, an introductory study. Panamá.

Krickeberg, Walter

1949 Felsplastik und Felsbilder bei den Kulturvölkern Altamerikas mit besonderer Berücksichtigung Mexicos, 1.

Palmen Verlag, Berlin.

Künne, Martin

2003a Präkolumbische Felsgravuren im Valle de El General, Costa Rica. Möglichkeiten und Grenzen der Aussagen über Bodendenkmäler mit Symbolcharakter. Tesis de Doctorado. Verlag Marie Leidorf, Rahden/Westf. Alemania. 
Lange, Frederick W. y Doris Stone (eds.)

1984 The archaeology of Lower Central America. University of New Mexico Press, Albuquerque.

Navarro Genie, Rigoberto

1996 Arte rupestre del Pacífico de Nicaragua. Las variables de las representaciones entre la costa del Pacífico y el Lago Cocibolca. (152 p.) Fondo Editorial INC/ASDI, Editorial UCA. Managua.

Pincemin Deliberos, Sophía

1999b De manos y soles. Estudio de la gráfica rupestre en Chiapas. Universidad de Ciencias y Artes del Estado de Chiapas, Tuxtla Gutiérrez, Chiapas.

Quilter, Jeffery y Aida Blanco

1992 Report on the 1992 archaeological investigation of the Rivas site, Costa Rica. Ms. Museo Regional del Sur, San Isidro de El General.

Robinson, Eugenia y Gene Ware

2001 Multi-spectral imaging of La Casa de las Golondrinas rock paintings. (Guatemala). Report submitted to the Foundation for the Advancement of Mesoamerican Studies (FAMSI). Publicación en internet, URL: http://www.famsi.org/reports/99052/index.html

Rowe, Marvin; Allan Cobb; Polly A. Peterson y Patricia McAnany

2002 Terminal Classic pictographs from Aktun Ik. En: McAnany, Patricia (ed.): Sacred land-scape and settlement in the Sibun river valley: XARP 1999 Archaeological survey and excavation, pp. 71-77. Institute for Mesoamerican Studies, Occasional Publication, 8. University at Albany, State University of New York, Albany.

Sapper, Carl

1900b Reise auf dem Rio Coco (nördliches Nicaragua). Besuch der Sumos und Mosquitos. En: Globus, 78(16): 249252, 78(17): 271-276. Braunschweig, Alemania (Reimpreso en el año 1902: Mittelamerikanische Reisen und Studien aus den Jahren 1888-1900, pp. 251-271. F. Vieweg und Sohn, Braunschweig, Alemania).

Schobinger, Juan

1997 Arte préhistorico de América. Milano, México Ciudad.

Schortman, Edward y Patricia Urban

2001 Interregional interactions. En: Evans, Susan T. y David L. Webster (eds.): Archaeology of Ancient Mexico and Central America, pp. 365-371. Garland Publishing, New York, London.

Seemann, Berthold

1866 On the resemblances of inscriptions found on ancient British rocks with those of Central America. Memoirs read before the Anthropological Society of London (1865-66), 2: 277-282 (10 ilustraciones). London.

Stone, Andrea

1995 Images from the Underworld. Naj Tunich and the tradition of Maya cave painting. Austin, Texas: University of Texas Press.

Stone, Andrea y Martin Künne

2003 Rock Art of Central America and Maya Mexico. En: Bahn, Paul y Angelo Fossati (eds.): Rock art studies, news of the world II, pp. 196-213. Oxbow Books, Oxford, Oakville. 
Stone, Doris

1948 The basic cultures of Central America. En: Steward, Julian (ed.): Handbook of South American Indians, 4: 169193. Smithsonian Institution, Bureau of American Ethnology, Washington, D.C.

Stone, Doris; Gerdt Kutschert y Günter Vollmer

1991 Atlas gráfico de la arqueología de América Central. Ms. inédito, reconstrucción de un manuscrito del año 1967, previsto de publicarse como Monumenta Americana, 5. Ibero-Amerikanisches Institut, Berlin.

Strecker, Matthias

1979 Rock Art of East Mexico and Central America. An annotated bibliography. Monograph 10. Institute of Archaeology, University of California, Los Angeles

Taboada Téllez, Freddy y Matthias Strecker

2002 Documentación y registro del arte rupestre. Contribuciones al Estudio del Arte Rupestre Sudamericano. La Paz, Bolivia.

Ware, Gene y James Brady

1999 Multispectral analysis of ancient maya pigments: Implications for the Naj Tunich corpus. En: National Gallery of Art, Center for the Advanced Study of the Visual Arts (eds.): June 1998 - May 1998: Record of activities and research reports, 19: 132-135. Washington, D.C.

Whitley, David (ed.):

2001 Handbook of Rock Art Research. Walnut Creek, Lanham, New York, Oxford: Altamira Press.

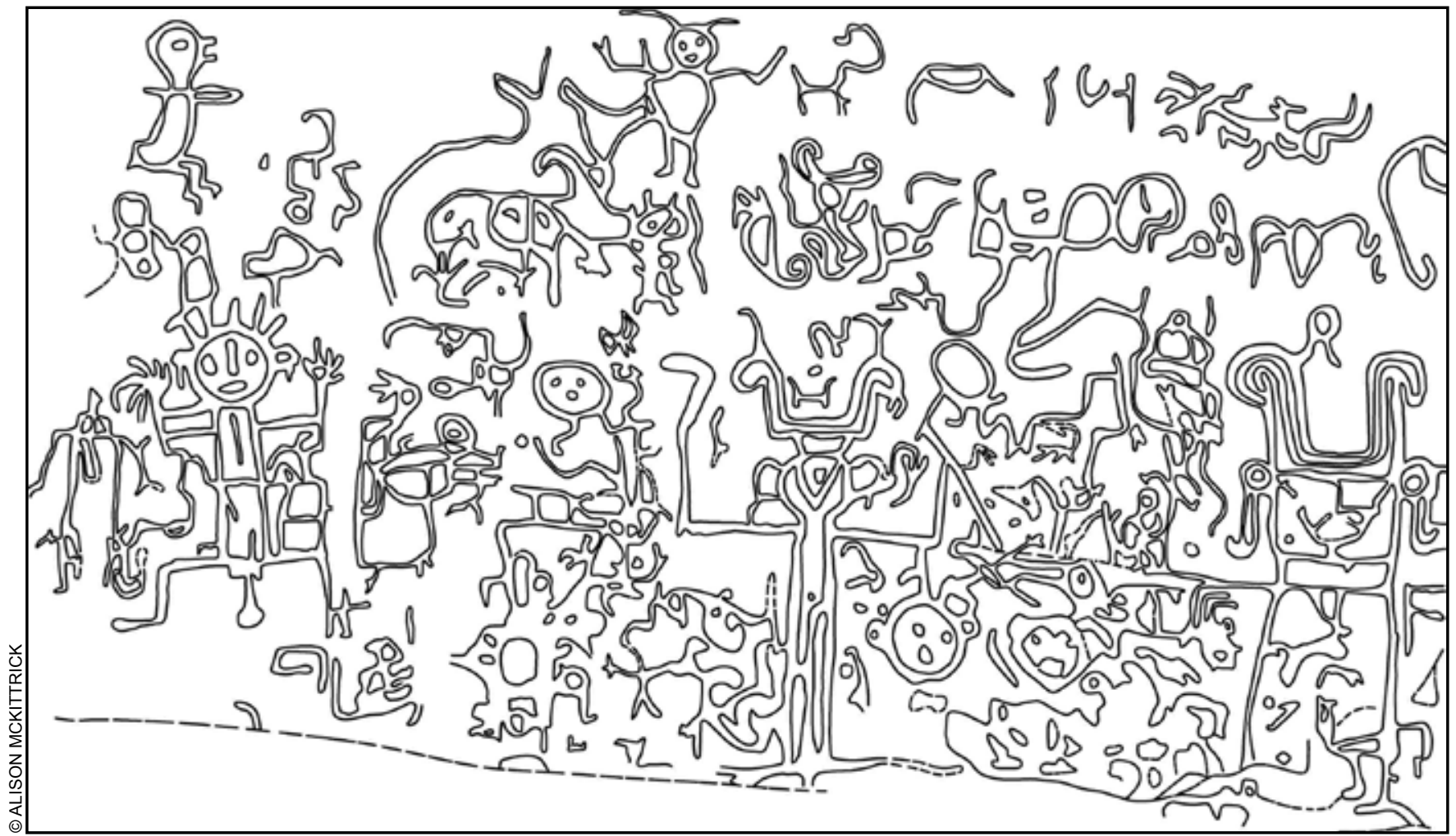

Grabados rupestres de Oropolí, Departamento de El Paraíso, Honduras. 